\title{
Rational Use of Microbiological Diagnostic Investigations: A Mini Report of a Cuban Current Experience
}

\author{
Lourdes Serrano García ${ }^{1 *}$, Glenis Damaris Fernández Reynaldo ${ }^{2}$ and Francisco López Roque ${ }^{2}$ \\ ${ }^{1}$ University of Medical Sciences of Holguin, Cuba \\ ${ }^{2}$ University of Holguin, Cuba
}

*Corresponding author: Lourdes Serrano García, University of Medical Sciences of Holguin, Cuba

\section{ARTICLE INFO}

Received: 幽 November 03, 2021

Published: 幽 November 10, 2021

\section{ABSTRACT}

Keywords: Higher medical education; Professional training; Medical microbiology; Microbiological diagnosis; Rationality

Citation: Lourdes Serrano García, Glenis Damaris Fernández Reynaldo, Francisco López Roque. Rational Use of Microbiological Diagnostic Investigations: A Mini Report of a Cuban Current Experience. Biomed J Sci \& Tech Res 39(5)-2021. BJSTR. MS.ID.006370.

\section{Introduction}

Microbiological diagnostic investigations constitute the examinations, techniques, tests, analytical procedures, which are carried out by the microbiology laboratory staff in a standardized manner to quickly and accurately offer information regarding the presence or absence of a microbial agent causing an infectious condition, as well as the results related to in vitro resistance tests against antimicrobials [1]. Its application varies depending on the clinical syndrome and the type of agent being considered, so its optimal use, in the author's opinion, implies the dynamic interaction of three factors: the existence of quality medical care, expertise in the laboratory execution and the effective doctor-laboratory staff relationship. It is the responsibility of the attending physician to deal with patients with clinical pictures suggestive of an infectious disease, to make presumptive diagnoses, indicate microbiological diagnostic investigations and initiate treatments. He requests how and when to collect the samples, informs the laboratory of the patient's history of antibiotic therapy and interpreting the results.
The benefits of the rational use of the microbiological resource can be expressed in indicators such as: accurate diagnoses of infectious diseases; the right one treatment of individual patients; microbiological surveillance and control; increased quality of life; environmental protection; optimal use of material and economic resources; which today constitutes a social task not solved by the medical sciences, since infectious diseases remain the leading causes of morbidity and mortality throughout the planet [2].

Teaching-learning of microbiological diagnostic investigations in the Medical career in Cuba, it is mainly consolidated through the Medical microbiology and parasitology subject, included in the Diagnostic Investigations discipline. However, in a study carried out previously by the authors at the University of Medical Sciences of Holguin [3], it was found that the dynamics of the teachinglearning process of the subject does not favor students to apply the contents related to the rational use of microbiological diagnostic investigations to their experiences. Consequently, the aspirations 
reflected in the professional model, regarding to the resolution of problems of the profession in which biological agents intervene by applying rationality, are not specified from the treatment of the objectives of this matter. In the same research, numerous limitations were determined regarding the degree of student application of actions that contribute to the rational use of microbiological diagnostic investigations in the setting of educational activities at work, related to: the realization of the presumptive diagnosis of a disease infectious in both second and sixth year students, with a greater contribution provided by those in the first group; problems in the optimal identification of the required microbiological diagnostic investigations; the orientation of the sample collection; communication with the patient and laboratory personnel; and the interpretation of laboratory results [3].

Regarding to the topic discussed, it should be noted that the economic planning of our country prioritizes the consolidation of the teaching and use of the clinical and epidemiological method so that they contribute to the rational use of technological means for the diagnosis and treatment of diseases [4]. In this sense, Martínez $Y$ [5] points out that the optimal use of technological resources during the diagnosis of nosocomial diseases, favors the consequent reduction of the economic burden that they represent for hospitals, at the same time that it contributes to the improvement of the quality of life of patients. The above agree with the report of Djulbegovic B, Elqayam S and Dale W [6], who assure that current medical care continues to be characterized by poor results, largely due to the excessive/under use of health and medical services resources. According to the findings of the study carried out by previous researchers, suboptimal decisions are considered the main cause of death and are responsible for more than $80 \%$ of health expenses.

\section{Final Considerations}

It is considered that the correct action, exercise and rationalization, is the main tool of science to solve specific problem situations. A deep analysis of the current facts, leads to the identification of theoretical and methodological limitations, as an element that reduces the possibilities of assuming a systematized and contextualized process of professional training of doctors regarding to the optimal use of microbiological diagnostic

\section{ISSN: 2574-1241}

DOI: $10.26717 /$ BJSTR.2021.39.006370

Lourdes Serrano García. Biomed J Sci \& Tech Res

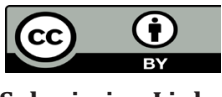

This work is licensed under Creative

Commons Attribution 4.0 License

Submission Link: https://biomedres.us/submit-manuscript.php investigations. In this sense, the scant didactic treatment given to the logic of the formative dynamics in this particular case is also considered a significant weakness. In order to solve this reality, it is essential to improve the epistemological basis of the teachinglearning of the Medical microbiology and parasitology subject with the aim to promote the optimal use of the organizational forms of teaching and the use of methods and means that favor the training of a professional at the height of contemporaneity.

\section{Acknowledgment}

All the authors wish to express their deep gratitude to the Financial and Editorial offices of the Biomedical Journal of Scientific \& Technical Research (BJSTR) for the complete financing of this paper.

\section{Competing Interests}

The authors do not declare competing interest.

\section{Author's contribution}

All authors have actively participated in the writing and critical review of the final version of the scientific text that supports the present research.

\section{References}

1. Serrano L, Fernández GD, López F (2020) Epistemic proposal for doctor custom of microbiological diagnostic investigations cultural formation. Didasc@lia: Didáctica y Educación 11(3): 14-26.

2. Serrano GL, Serrano GL, Rodríguez AJ (2020) New perspective for the teaching-learning of the microbiological diagnostic investigations in Medical career. Rev Panorama Cuba y Salud 15(3): 108-109.

3. Serrano L, Fernández GD, López F (2021) Perceptions regarding to the dynamics of cultural training of the use of microbiological diagnostic Investigations. Rev Argentina de Edu Médica 10(3): 27-37.

4. (2015) Ministry of Public Health. Diagnostic Investigation discipline program, Curriculum D. National Commission of Medical career. Havana, Cuba.

5. Martínez Y (2017) Impact of health care associated infections on the cost and quality of medical care at the Holguin Provincial Pediatric Hospital in the period 2012-2016. Thesis, University of Holguin, Cuba.

6. Djulbegovic B, Elqayam S, Dale W (2018) Rational decision making in medicine: Implications for overuse and underuse. Journal of evaluation in clinical practice $24(3)$ : 655-665

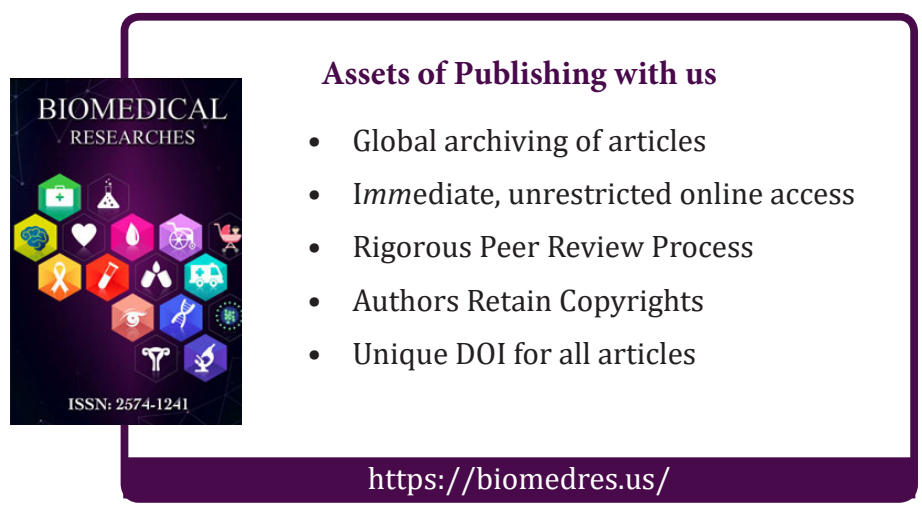

